\title{
THERMOFORMING PROCESS PARAMETER OPTIMIZATION of THERMOPLASTIC PEKK/CF and PPS
}

\author{
Merve COBANOGLU ${ }^{1}$ *(i), Remzi Ecmel ECE ${ }^{2}$ (i), Fahrettin OZTURK ${ }^{3}$ \\ 1,2 Türk Havacılık ve Uzay Sanayii A.Ş., Ankara \\ ${ }^{3}$ Türk Havacılık ve Uzay Sanayii A.Ş., Ankara Yıldırım Beyazıt Üniversitesi, Ankara
}

\begin{abstract}
Thermoplastic composite parts in the aerospace industry have recently increased due to the reshaping and reusing potentials of thermoplastic composite materials. The thermoforming process is one of the effective manufacturing methods to form thermoplastic composite materials. The main benefits of the process are low cost and short process time. Optimization of the process parameters is essential to produce accurate parts. In this present study, effects of plate geometry and connection technique, preheating, and pressing parameters are investigated experimentally for the thermoforming of Poly Ether Ketone Ketone / Carbon Fiber (PEKK / CF) and Polyphenylene Sulfide (PPS) sheets. Results reveal that wrinkle and warping problems of the formed sheets are minimized by optimization of these parameters.
\end{abstract}

Keywords: Thermoplastic, Thermoforming, PEKK, PSS

\section{INTRODUCTION}

Composite materials are significant and attractive for many industries, especially for the aerospace industry. The superior mechanical properties and the substantial weight reduction in systems are the main reasons for their attractiveness [1]. Moreover, composites can provide comparable performance to conventional metallic materials while decreasing the weight from 10 to 50\% [2]. Not only weight but also cost reduction is possible from 10 to $20 \%$ using composite instead of metallic materials [3]. Thermoset materials are widely used in the aerospace industry. However, the production of thermoset composites consists of many stages, which are obstacles to rapid production. Thermoplastics have got significant attention in primary aircraft parts due to their fast production advantage [4].

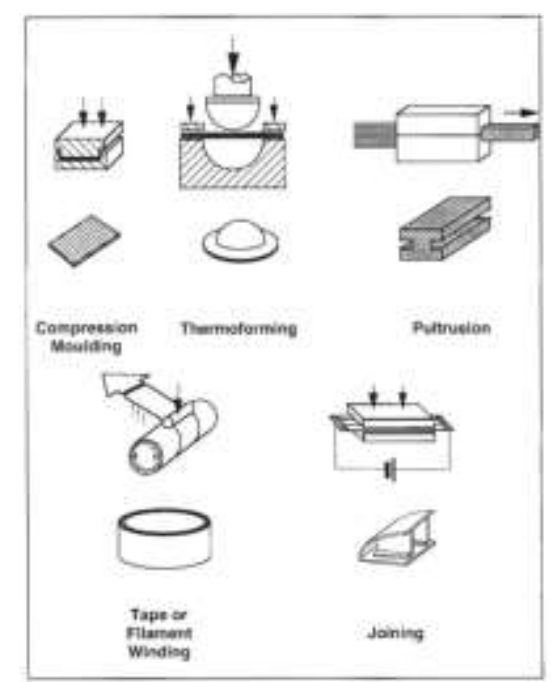

Figure 1. Processing methods for thermoplastic composites [6] 
There are many manufacturing methods developed for thermoplastic composites [5]. Some of these processes are generally used for thermosetting composites and sheet metal forming, but these fabrication techniques such as compression molding, tape winding, thermoforming, joining, and pultrusion have become for the thermoplastic composites (Figure 1) [6].

The aerospace industry is particularly interested in the press forming (thermoforming) of thermoplastic materials for rapid production [7]. Press forming is a type of 'thermoforming,' a set of processes for shaping a blank that has been melted by an oven and consists of three main steps: preheating, forming, and cooling.

Preheating is categorized as infrared (radiation) heating, contact or conduction heating, or convection heating, depending on how heat is applied to the blank. While contact heating is the most effective form of heating, and convection heating allows for the most uniform temperature distribution, contact heating fails in practical use due to bonding between tool and blank. Convection heating is slow and inefficient, lagging behind infrared heating. In the scope of rapid manufacturing, the most crucial parameter is the overall process time. $[8,9]$ Infrared heating allows for a quick preheating process, reducing overall process time while providing great convenience and flexibility.

Blanks are heated over the melting temperature and transferred from the oven to the hot press system to form the pre-consolidated blanks into a 3-D shape. However, forming for thermoplastic composites have also some issues. It can be a restrictive aspect of whether the defects like warping and wrinkle can occur while processing. Wrinkles and warpage can cause damages that make the produced part a scrap. Moreover, the material defects which may not be noticed could cause catastrophic failure. Production parameters and processes must be examined precisely without errors since aircraft components have to comply with aviation regulations completely.

In the presented study, blank geometry, connection technique (blank to frame), heating, and pressing parameters are optimized to resolve the problems.

\section{EXPERIMENTAL PROCEDURE}

In this study, PPS and PEKK thermoplastic blanks were used. The aerospace-grade materials were supplied from TenCate and ATC companies. Sheets were formed at the Turkish Aerospace Thermoplastic Research Laboratory.

As mentioned earlier that preheating before shaping is essential for thermoplastics. Therefore, experiments were carried out in an IR oven. It is closed on four sides and has two tip-up gates, upper and lower heater sections. Each of these sections consists of $120-\mathrm{mm}$ by $120-\mathrm{mm} 25$ ceramic heaters. Upper and lower sections can be controlled to set distances between surfaces of plate and heaters by servo motors, as seen in Figure 2 (a). Heaters in each section are divided into two groups to heat different controlled zones utilizing an embedded PID (Proportional integral derivative) control unit 


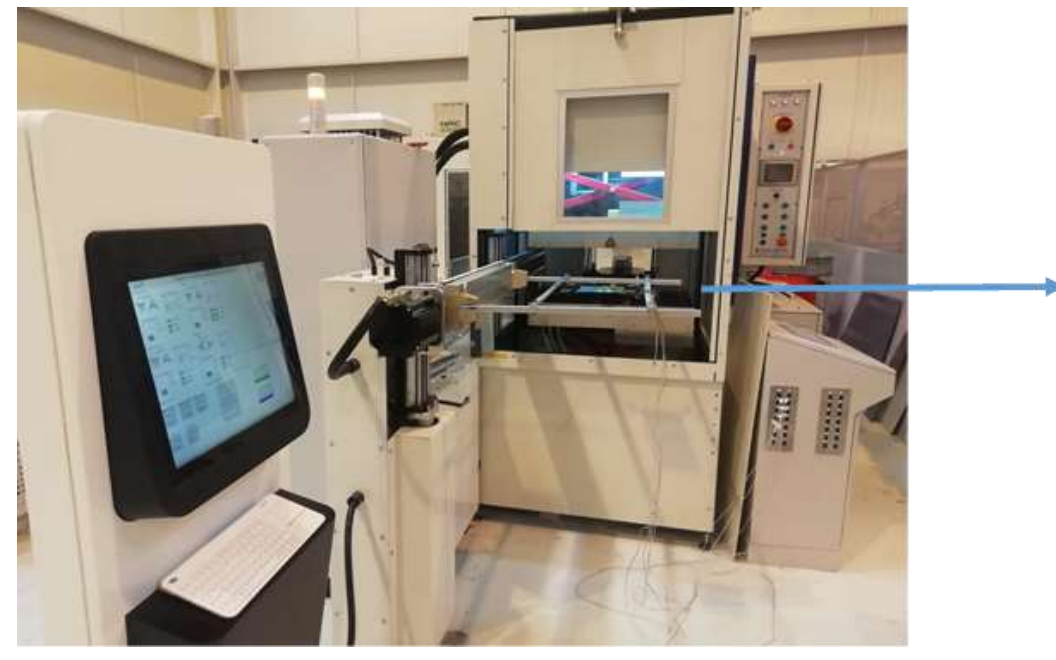

(a)

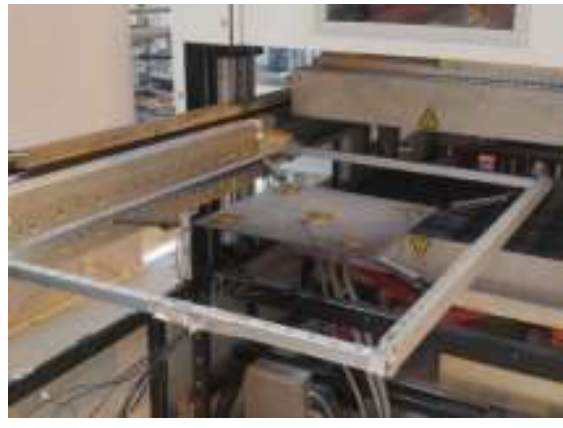

(b)

Figure 2. (a) Control and heating unit; (b) Experimental setup and the thermoplastic sheet attached to the frame

In PLC controlled PC, desired temperature, blank distance, heating ramp-up values were set. The temperature was checked by the system using Type-K thermocouples, which are placed inside of the heaters. When heaters reached that value, the blank was sent to the oven. The blank is held by springs from the corners to prevent materials from necking because of softening during heating. Holes were drilled in the four corners of the blank and connected to the frame with springs, as shown in Figure 2(b).

When the oven reached the desired temperature, the frame was sent, and the gates were closed. After a few minutes, the thermoplastic blank reaches the process temperature above the melting point. The molten blank was ready to be shaped. Therefore, it was left in the oven and moved under the press. When the frame located under the upper press side of the tool moved down, and the blank was stamped a few minutes between the press tool after the required time passed, the shaped blank was removed from the frame, and the thermoforming process thermoplastic composites was completed.

\section{RESULTS AND DISCUSSION}

In this paper, PPS and PEKK thermoplastic composites were used for the aircraft rib production process. It is necessary to fulfill the required mechanical properties. Therefore, it is required to find optimum parameters to get desired properties. The part should pass all required tests.

In Table 1, IR was preheating, and IR instant heating was compared. In IR preheating, the PPS plate has $51.9 \%$ faster heating to reach the steady-state temperature $\left(\boldsymbol{t}_{\boldsymbol{s} s}\right), 8.63 \%$ higher plate temperature at steady state $\left(\boldsymbol{T}_{\text {ss,plate }}\right), 56.4 \%$ smaller temperature difference $\left(\Delta T_{s s}\right)$ and $82.9 \%$ lower power consumption $\left(\boldsymbol{q}_{\boldsymbol{a v g}}\right)$. These results were expected because IR heaters consume massive power to heat themselves first in IR instant heating, and the heated air contributes to heat the PPS plate faster. The critical issue is heating time for the part productions. As a result, IR preheating is more efficient for mass production and reduction of cycle time 
Table 1. Results of Exp.1, Variable parameter: Heating method

\begin{tabular}{ccccc}
\hline & $\boldsymbol{t}_{\boldsymbol{s} \text { s }}(\boldsymbol{s e c})$ & $\boldsymbol{T}_{\boldsymbol{s s}, \text { plate }}\left({ }^{\circ} \boldsymbol{C}\right)$ & $\Delta T_{\text {SS }}$ & $\boldsymbol{q}_{\text {avg }}$ (watt) \\
\hline $\begin{array}{c}\text { IR } \\
\text { preheating }\end{array}$ & 380 & 200 & 300 & 500 \\
$\begin{array}{c}\text { IR instant } \\
\text { heating }\end{array}$ & 430 & 260 & 200 & 500 \\
\hline
\end{tabular}

The part was successfully processed, as seen in Figure 3.

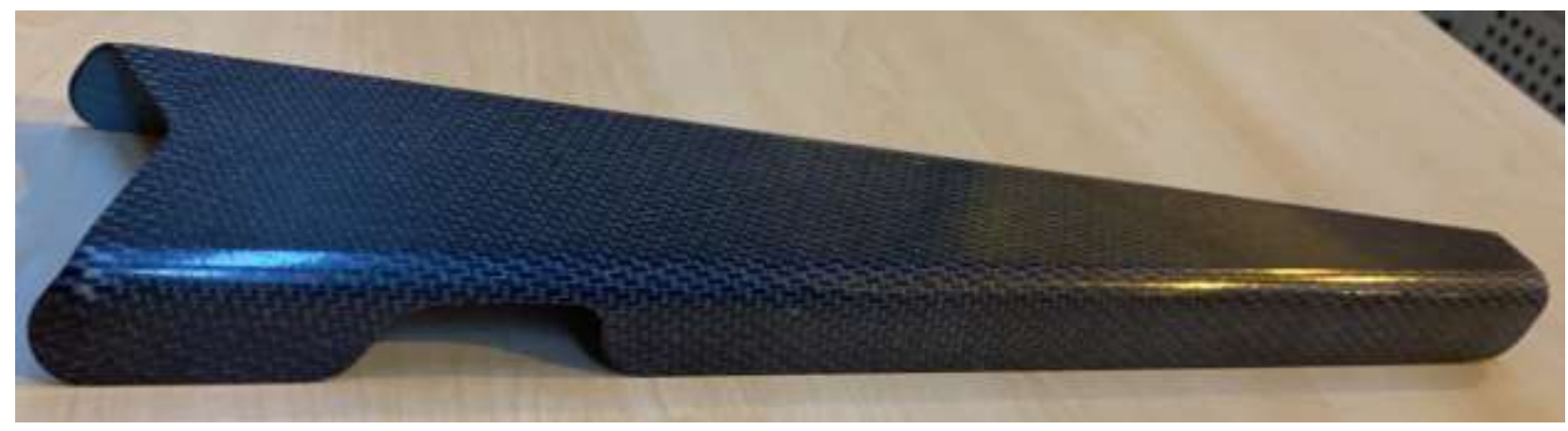

Figure 3. Produced aircraft rib

Based on experimental results, essential parameters were determined and optimized, i.e., heating temperature, heating time, and tooling temperature (Table 2). Degree of crystallinity tests was performed for thermoformed ribs, and results are shown in Figure 5. The expected percent of crystallinity values between $23-27 \%$ were achieved, and these values are sufficient to enable required mechanical properties. A summary of the degree of crystallinity is given in Table 3.

Table 2. Summary of optimum process parameters

\begin{tabular}{cccccc}
\hline Material & $\begin{array}{c}\text { Oven Set } \\
\text { Temperature } \\
\left({ }^{\circ} \mathbf{C}\right)\end{array}$ & $\begin{array}{c}\text { Tool Set } \\
\text { Temperature } \\
\left({ }^{\circ} \mathbf{C}\right)\end{array}$ & $\begin{array}{c}\text { Preheating } \\
\text { time }(\mathbf{s})\end{array}$ & $\begin{array}{c}\text { Pressure } \\
(\mathbf{p s i})\end{array}$ & $\begin{array}{c}\text { Time (tool) } \\
(\mathbf{s})\end{array}$ \\
\hline PPS & 380 & 200 & 300 & 500 & 150 \\
PEKK & 430 & 260 & 200 & 500 & 130 \\
\hline
\end{tabular}

Table 3. Summary of the degree of crystallinity

\begin{tabular}{ccccc}
\hline Sample Name & $\begin{array}{c}\text { Sample Weight } \\
(\mathbf{m g})\end{array}$ & $\begin{array}{c}\text { Resin } \\
\text { Content(\%) }\end{array}$ & $\begin{array}{c}\text { Percent } \\
\text { Crystallinity } \\
(\%)\end{array}$ & $\begin{array}{c}\text { Melting } \\
\text { Temperature } \\
\text { Peak }\left({ }^{\circ} \mathbf{C}\right)\end{array}$ \\
\hline $\begin{array}{c}\text { Blank Panel } \\
\text { (BT) Run1 }\end{array}$ & 17.80 & 43 & 23.66 & 284.32 \\
$\begin{array}{c}\text { Blank Panel } \\
\text { (BT) Run2 }\end{array}$ & 17.70 & 43 & 23.88 & 283.92 \\
$\begin{array}{c}\text { Blank Panel } \\
\text { (BT) Run3 }\end{array}$ & 18.90 & 43 & 26.21 & 283.46 \\
$\begin{array}{c}\text { Rib Trial-2 } \\
\text { (T2) Run1 }\end{array}$ & 17.50 & 43 & 24.07 & 281.78 \\
$\begin{array}{c}\text { Rib Trial-2 } \\
\text { (T2) Run2 }\end{array}$ & 16.50 & 43 & 24.80 & 282.61 \\
\hline
\end{tabular}


Cobanoglu et al. / Eskişehir Technical Univ. J. of Sci. and Tech. A-Appl. Sci. and Eng. Vol. 22 - 2021 8th ULPAS - Special Issue 2021

Rib Trial-2

(T2) Run3

17.30

43

23.72

281.41

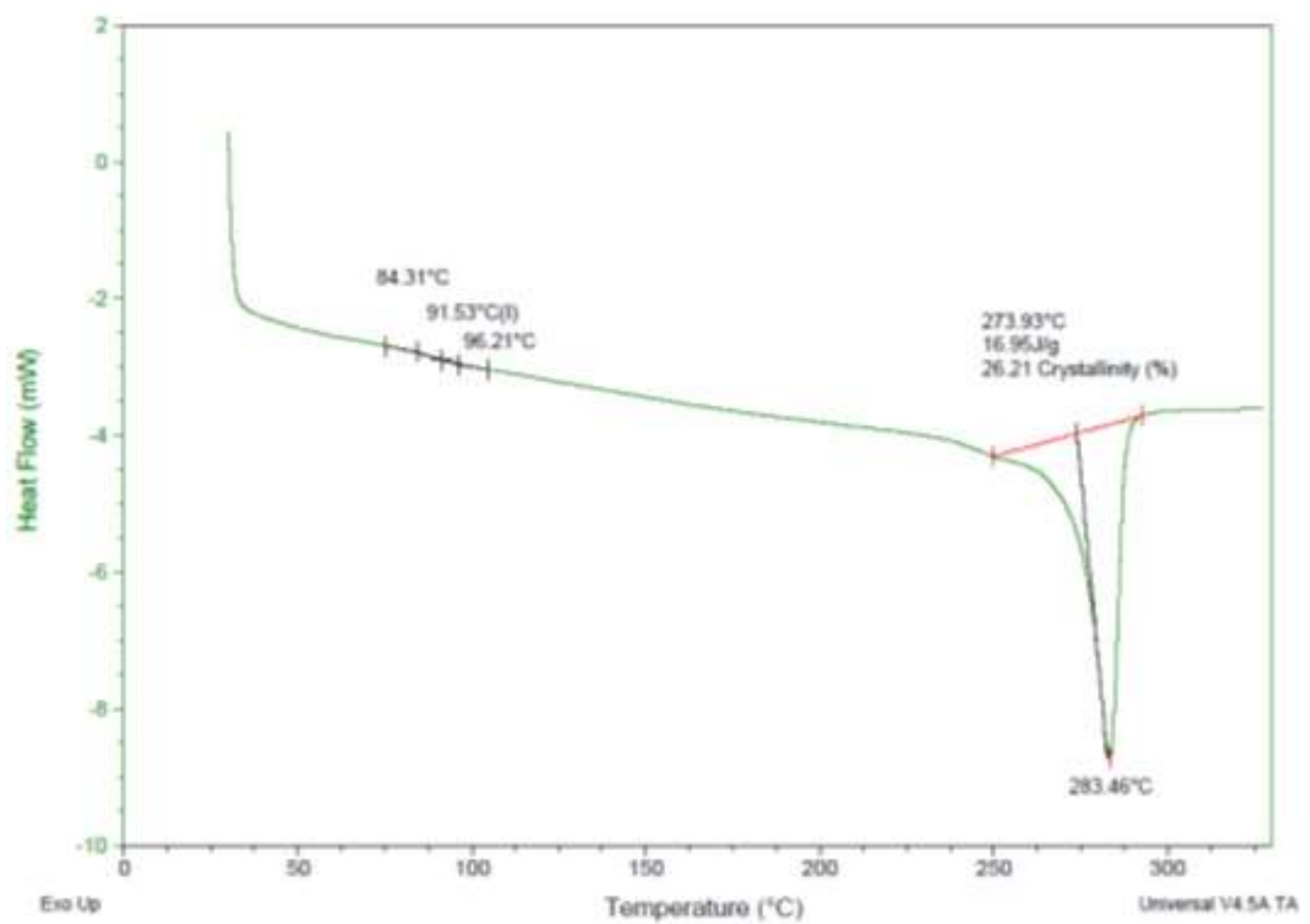

Figure 4. Degree of crystallinity graph

Micro-cut measurements (thickness measurements) of the surface profile were performed at different points from the web and both flanges of the part with a ball-ball micrometer (Figure 5.). It was observed that the thickness difference is within the acceptable tolerances. All the measurement data were tabulated in Table 4. 


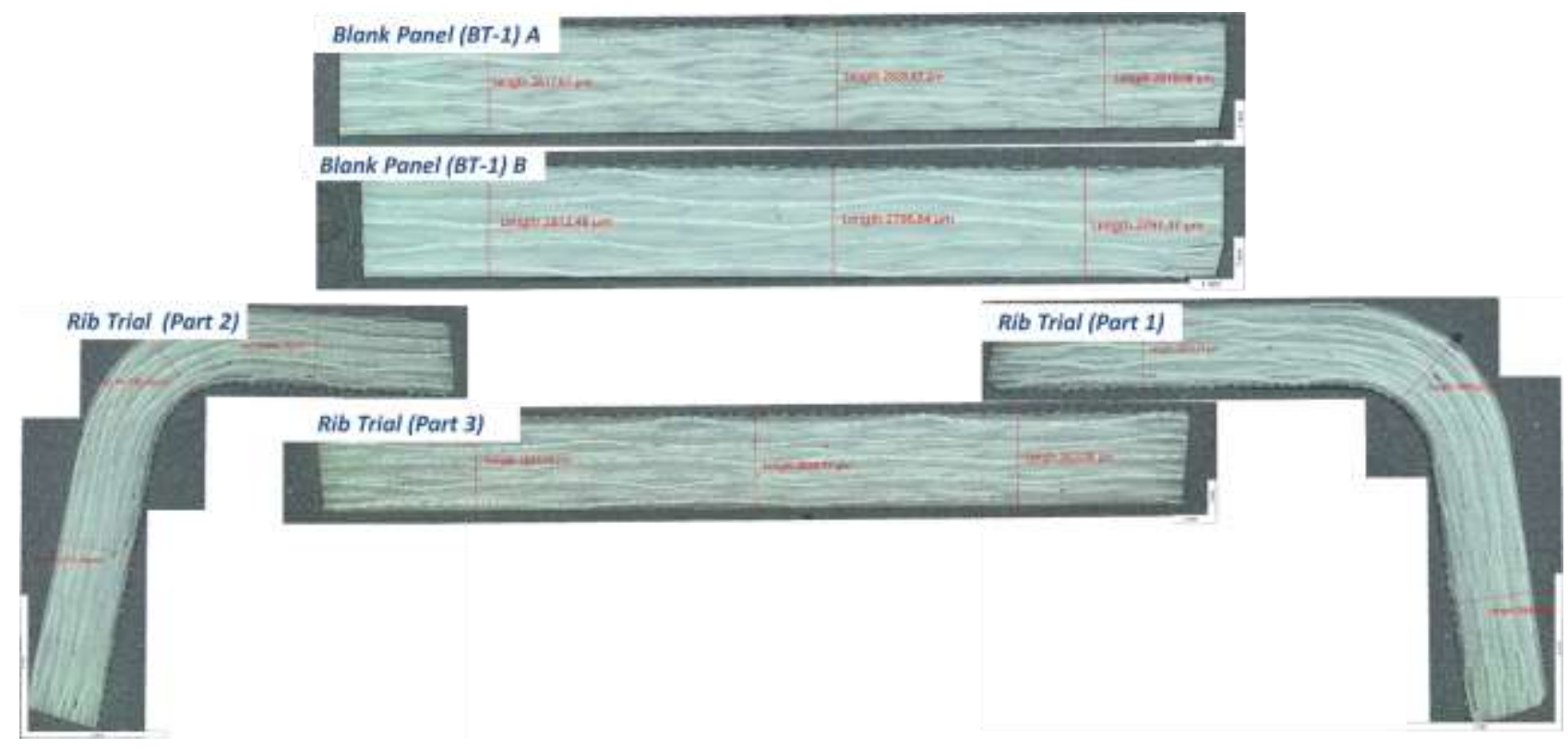

Figure 5. Micro-cut measurements of the PPS RIB

Table 4. Thickness measurements

\begin{tabular}{ccccccc}
\hline \multicolumn{2}{c}{ Zone 1 $(\boldsymbol{\mu \mathbf { m } )})$} & Zone 2 $(\boldsymbol{\mu \mathbf { m } )}$ & $\begin{array}{c}\text { Zone 3 } \\
(\boldsymbol{\mu m})\end{array}$ & $\begin{array}{c}\text { Deviation } \\
\text { Zone 1 }(\boldsymbol{\%})\end{array}$ & $\begin{array}{c}\text { Deviation } \\
\text { Zone 2 }(\boldsymbol{\%})\end{array}$ & $\begin{array}{c}\text { Deviation } \\
\text { Zone 3 }(\boldsymbol{\%})\end{array}$ \\
\hline Blank Panel A & 2817 & 2828 & 2818 & -0.46 & -0.07 & -0.42 \\
Blank Panel B & 2812 & 2796 & 2791 & -0.64 & -1.20 & -1.38 \\
Rib Trial (Part 1) & 2853 & 2809 & 2809 & 0.81 & -0.74 & -0.74 \\
Rib Trial (Part 2) & 2840 & 2831 & 2776 & 0.35 & 0.04 & -1.91 \\
Rib Trial (Part 3) & 2837 & 2826 & 2823 & 0.25 & -0.14 & -0.25 \\
\hline
\end{tabular}

In addition to DSC and micro-cut analysis, tensile tests were also applied to PEKK and PPS samples to investigate their mechanical performance. Tensile tests were performed at the INSTRON testing machine. There were five samples prepared for each composite (PEKK and PPS) according to the ASTM D3171 - 99. Tensile tests were performed at room temperature and $5 \mathrm{~mm} / \mathrm{min}$ deformation speed. Results of these tensile tests are given in Figure 6 and Table 5. These results were average values of 5 samples.

Table 5. Tensile test results of the PEKK and PPS rib parts

\begin{tabular}{ccc}
\hline & Ave. Tensile Strength (MPa) & Ave. Elastic Modulus (GPa) \\
\hline PEKK & $823.7 \pm 63.2$ & $24.3 \pm 0.3$ \\
PPS & $607.7 \pm 17.3$ & $23.1 \pm 0.8$ \\
\hline
\end{tabular}




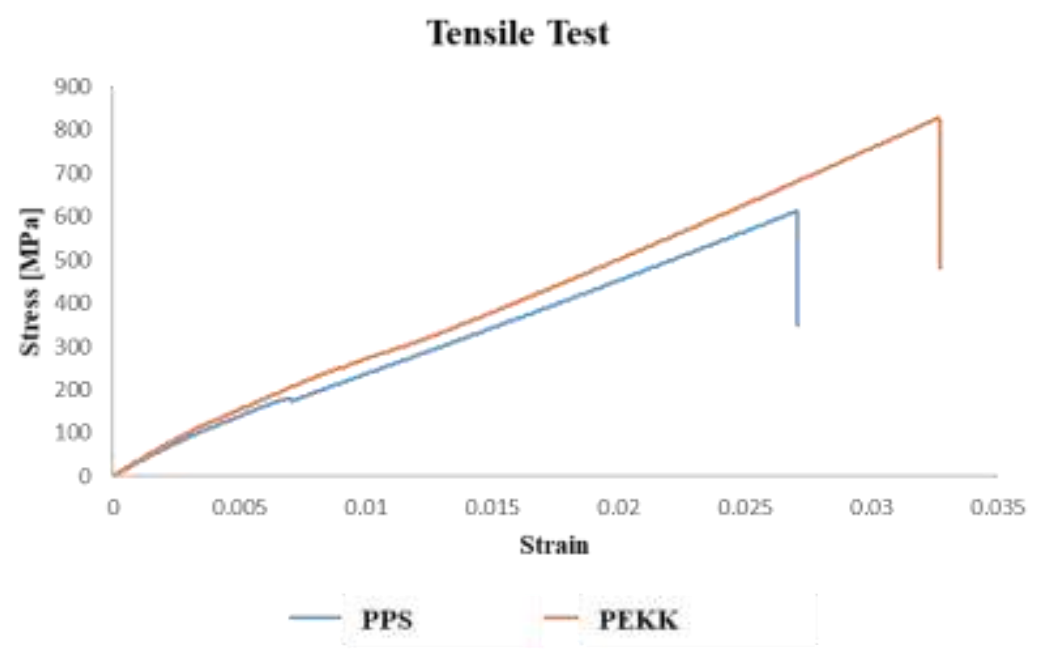

Figure 6. Tensile test results of PEKK and PPS thermoplastics

As seen from the results, the tensile strength of the PEKK is greater than PPS. Average tensile strength $(608 \mathrm{MPa})$ and elastic modulus (23 GPa) of the PPS were observed. These results have complied with the literature [10]; therefore, it can be concluded that thermoforming process of PPS does not affect the mechanical properties. Moreover, tensile strength and elastic modulus results of the PEKK composite (824 MPa; $24 \mathrm{GPa}$ ) were also similar to the literature [11]. It shows that during thermoforming, the mechanical properties of the PEKK thermoplastic composite were also conserved. No significant change was recorded. As a result, selected thermoforming parameters for PEKK and PPS were accepted as optimum since their thermal and mechanical properties are not changed after they are shaped.

\section{CONCLUSIONS}

Thermoplastic composite materials are quite important for the aerospace industry, because of their superior advantages compared to metals and thermoset composites. Thermoforming is a standard method used for the shaping of thermoplastics. However, the thermoforming process has many parameters, and optimizing these parameters is critical for each material and part of the aircraft. This paper studied the thermoforming process of two different thermoplastic composites, e.g. PEKK and PPS. These two were selected since they are widely used in aircraft structures. After studying several parameters, the optimum of thermoforming parameters (temperature, pressure, time, etc.).

Results indicated that wrinkle and warping problems of the thermoformed sheets are minimized by parameter optimization. The most optimum parameters were determined.

\section{FUTURE WORKS}

This study was completed using consolidated blanks. In the future, the primary goal is to study consolidation, i.e., producing blanks from semi-crystalline pre-preg under high temperature and pressure conditions.

\section{ACKNOWLEDGEMENT}

This study is supported by Turkish Aerospace Industries Inc.'s 1515 - The Scientific and Technological Research Council of Turkey (TÜBİTAK) Frontier R\&D Laboratory Support Programme, Project\# 5189901. 


\section{CONFLICT OF INTEREST}

The author stated that there are no conflicts of interest regarding the publication of this article.

\section{REFERENCES}

[1] Cunningham JE, Monaghan PF, Brogan MT, and Cassidy SF. Modeling of preheating of flat panels prior to press forming, Compos. Part A Appl. Sci. Manuf., 1997; vol. 28, no. 1, pp. 17-24.

[2] Suong DG, Stephen VH, Tsai W. Composite Materials Design and Applications. CRC PRESS, 2003.

[3] Abbasi F, Elfaleh I, Mistou S, Zghal A, Fazzini M, \& Djilali T. Experimental and numerical investigations of a thermoplastic composite (carbon/PPS) thermoforming. Structural Control and Health Monitoring, 18, May 2011; 769-780. https://doi.org/10.1002/stc

[4] Muzzy JD, Kays AO. Thermoplastic vs. thermosetting structural composites, Polymer Composites, 1984; vol. 5, no. 1, pp. 69-172.

[5] Cogswell FN, Thermoplastic Aromatic Polymers; Butterworth-Heinemann Ltd., Oxford, 1992; 124-139.

[6] Friedrich K, Hou M, \& Krebs J. Chapter 4 Thermoforming of continuous fibre/thermoplastic composite sheets. Composite Materials Series, 1997; 11(C), 91-162. https://doi.org/10.1016/S0927-0108(97)80006-9

[7] Offringa AR. Thermoplastic applications composites-rapid processing applications, Compos. Part A, 1996; vol. 27(A), pp.329-336,

[8] Dutch Thermoplastic Composites “Aerospace Structures," http://www.composites.nl/ products/aerospace-structures/.

[9] Saraiva F. Development of press forming techniques for thermoplastic composites Investigation of a multiple step forming approach, MSc Thesis in Aerospace Engineering Structural Integrity \& Composites, TU Delft, 2017.

[10] Chukov D, Nematulloev S., Zadorozhnyy M, Tcherdyntsev V, Stepashkin A \& Zherebtsov D. Structure, mechanical and thermal properties of polyphenylene sulfide and polysulfone impregnated carbon fiber composites. Polymers, 2019; 11(4), 684.

[11] Salek MH. Effect of processing parameters on the mechanical properties of carbon/PEKK thermoplastic composite materials (Doctoral dissertation, Concordia University), 2005. 